\title{
Satisfação no trabalho versus resultado contábil: estudo de caso em uma cooperativa de crédito
}

\author{
Job satisfaction versus accounting results: case study in a credit union
}

\author{
Sonia Raifur Kos', Evandro Thiago Padilha" \\ 'Universidade Estadual do Centro Oeste - UNICENTRO. soniarkos@yahoo.com.br \\ " Universidade Estadual do Centro Oeste - UNICENTRO. evandrothiago2604@gmail.com
}

\section{RESUMO}

O presente estudo teve por objetivo verificar o nível de satisfação no trabalho e se o mesmo tem relação com o resultado contábil atingido. Foi utilizada metodologia quantitativa e descritiva, com coleta de dados por meio de aplicação de questionário em uma cooperativa de crédito, com a participação de 102 respondentes. Os participantes deram uma nota entre 1 e 7 para cada uma das questões, onde a nota de 1 a 3 vai de muito insatisfeito até insatisfeito, nota 4 indica que o quesito é indiferente, seria o equilíbrio entre estar satisfeito ou insatisfeito e por fim, as notas de 5 a 7 correspondem de satisfeito até muito satisfeito. Os resultados indicam que, quanto ao nível de satisfação os resultados mostram que, de forma geral, os colaboradores se mostram satisfeitos, visto que a maior parte das respostas se concentra nas notas 6 e 7. Percebe-se que as dimensões "Relação com Colegas", "Chefia" e "Natureza do Trabalho" há maior satisfação quando comparado com as dimensões de "Salários" e "Promoções". Quanto aos "Salários", somente 9,6\% das notas ficaram concentradas na nota mais alta. Quanto a correlação, os resultados não se mostraram significativos, evidenciando a não relação entre o Nível de Satisfação e o Desempenho econômico e financeiro auferido.

Palavras-chave: satisfação no trabalho; cooperativa de crédito; desempenho econômico e financeiro.

\section{ABSTRACT}

The present study aimed to verify the level of job satisfaction and whether it is correlated with the accounting result reached. A quantitative and descriptive methodology was used, with data collection through questionnaire application, in a credit cooperative, with the participation of 102 respondents. The participants gave a score between 1 and 7 for each of the questions, where the score from 1 to 3 
goes from very dissatisfied to dissatisfied, note 4 indicates that the question is indifferent, it would be the balance between being satisfied or dissatisfied and finally, grades 5 to 7 correspond from satisfied to very satisfied. The results indicate that, in terms of level of satisfaction, the results show that, in general, employees are satisfied, since most of the answers are concentrated in notes 6 and 7. It is noticed that the dimensions "Relation with Colleagues "," Leadership "and" Nature of Work "there is greater satisfaction when compared to the dimensions of" Salaries "and" Promotions ". As to "Salaries", only $9.6 \%$ of the scores were concentrated in the highest grade. Regarding the correlation, the results were not significant, evidencing the non-relation between the Level of Satisfaction and the Economic and Financial Performance.

Keywords: job satisfaction; credit cooperative; economic and financial performance.

\section{INTRODUÇÃO}

Desde o seu surgimento no ano de 1844 o cooperativismo tem assumido papel muito importante na sociedade, buscando alcançar os melhores resultados para os cooperados e manter o seu foco na sociedade que é, de fato, a sua razão de ser. Segundo a Organização das Cooperativas Brasileiras - OCB (2018) existe atualmente 2,6 milhões de cooperativas no mundo, o sistema cooperativo está presente em cem países e congrega um bilhão de pessoas e cresce em todos os ramos em que atua.

Diferentemente da maioria das empresas que buscam lucros a qualquer custo, as cooperativas priorizam as pessoas que estão envolvidas no processo, desde os colaboradores responsáveis por operacionalizar as atividades, até os seus cooperados, independentemente do montante de capital possuído. Essa valorização das pessoas está explicito em dois dos sete princípios instituídos pela primeira cooperativa: o primeiro está relacionado a "educação, formação e informação" indicação real da preocupação com futuro dos colaboradores e associados; e o segundo se traduz no "interesse pela comunidade", a qual também é formada pelos colaboradores, associados e todos os demais membros (OCB, 2018).

Não existe cooperativismo sem o compartilhamento de ideias (OCB, 2018). De acordo com os valores cooperativos ninguém perde quando todo mundo ganha. De fato, o objetivo principal do cooperativismo é gerar benefícios próprios e ao mesmo tempo fortalecer o todo. Nesse contexto de valorização humana ao invés da 
valorização do capital, as cooperativas vêm obtendo cada vez mais resultados positivos e ganhando espaço e reconhecimento da sociedade. Mesmo com toda a evolução tecnológica as cooperativas mantém seus princípios e valores pelos quais foram fundadas (OCB, 2018).

A preocupação com o desempenho e a forma de como melhorá-lo, segundo Masiero (2008), é um fator relevante e requer atenção, pois os resultados organizacionais mantem a empresa viva. O resultado obtido pelas empresas possui participação primordial das pessoas que estão envolvidas, sendo elas clientes, gestores ou colaboradores. Esse resultado esperado depende da forma que as pessoas se relacionam profissionalmente, além de fatores físicos como, por exemplo, a satisfação no trabalho, a qual, segundo Siqueira (2008) está associada com experiências positivas e prazerosas dentro da empresa.

Para Bion (2004) um dos aspectos que afeta fortemente a produtividade, e, consequentemente, o resultado das empresas é a satisfação do trabalhador. Segundo Robbins (2002), colaboradores satisfeitos estão mais dispostos a ajudar os demais e superar as expectativas em relação a seu trabalho, indo além de suas atribuições regulares. Azevedo e Egito (2012) mencionam que as consequências da satisfação no trabalho influenciam de forma significativa elementos como eficiência, produtividade, níveis de absenteísmo, comprometimento e relacionamento, impactando de forma positiva na saúde e bem-estar dos trabalhadores.

Nesse sentido, é importante que os líderes da organização conheçam o nível de satisfação dos mesmos, o qual, segundo a Escala de Satisfação no Trabalho - EST, proposta por Siqueira (2008), pode ser mensurada levando em consideração cinco aspectos: Colegas de Trabalho, Salário, Chefia, Natureza do Trabalho e Promoções.

Considerando que as cooperativas têm nos seus princípios um modo próprio de gestão, o qual, dentre outras coisas, valoriza as pessoas e, em paralelo, estudos 
mostram que a satisfação no trabalho influencia fortemente na produtividade e, portanto, no resultado a presente pesquisa visa inicialmente verificar o nível de satisfação dos colaboradores de uma cooperativa de crédito, com intuito de responder a seguinte questão de pesquisa: Qual o nível de Satisfação no Trabalho dos colaboradores de uma cooperativa de crédito e sua relação com o resultado contábil? Dessa forma, o objetivo geral do estudo é identificar o nível de satisfação dos colaboradores de uma empresa cooperativa e sua relação com o resultado contábil.

O conhecimento do nível de satisfação no trabalho é um aspecto fundamental e está se tornando uma exigência nas organizações bem-sucedidas (NODARI et al, 2010). Os gestores precisam compreender as atitudes de seus funcionários, as quais servem de indicadores de problemas potenciais. Trabalhadores satisfeitos se comprometem de forma mais intensa no cumprimento dos objetivos e metas organizacionais, direcionando suas energias de forma positiva para realizar os propósitos da empresa (HEDLER; CASTRO, 2017).

Vê-se, portanto, que o conhecer do nível de satisfação dos colaboradores e como isso pode se refletir no resultado econômico-financeiro é relevante tanto como aprofundamento no acervo teórico, bem como na atuação prática das empresas.

\section{REVISÃO DE LITERATURA}

\subsection{0 cooperativismo}

O cooperativismo possui uma grande história e tem suas origens no ano de 1844 em uma cidade inglesa chamada de Rochdale, a primeira cooperativa foi fundada por 28 tecelões que buscavam uma alternativa para sobreviver à exploração sofrida pelo sistema capitalista (SANTOS et al, 2012). Segundo os autores, as cooperativas possuem como objetivo atender a necessidade dos seus cooperados e estimular o crescimento da comunidade onde estão inseridas. 
O cooperativismo evoluiu muito desde sua constituição até chegar à forma como é hoje, porém seus princípios são os mesmos de sua origem: adesão voluntária e livre, gestão democrática, participação econômica dos membros, autonomia e independência, educação, formação e informação, intercooperação e o interesse pela comunidade (OCB, 2018).

Observando estes sete princípios as cooperativas vêm crescendo e ganhando seu espaço na sociedade. Segundo dados do Sistema OCB existem hoje treze ramos do cooperativismo, sendo eles: agropecuário, crédito, especial, habitacional, mineral, saúde, transporte, consumo, educacional, infraestrutura, produção, trabalho e turismo e lazer. Ressalta-se que esse estudo é realizado em uma cooperativa de crédito.

De acordo com Pinheiro (2008), a primeira cooperativa de crédito surgiu em 1847, criada por Friedrich Wilhelm Raiffeisen, no povoado de Weyerbusch/Westerwald. Foi a primeira forma de cooperativismo de crédito até chegar ao modelo existente hoje, era ali que começava a surgir os primeiros traços do cooperativismo de crédito.

No Brasil o cooperativismo de crédito surgiu no ano de 1902, em meio a necessidade de fomentar e auxiliar aos pequenos produtores da região. Surgia em 28 de dezembro de 1902 na localidade de Linha Imperial, atual município de Nova Petrópolis no estado do Rio Grande do Sul a primeira Cooperativa de Crédito, que continua em atividade até os dias atuais com o nome de Sicredi Pioneira RS (https://cooperativismodecredito.coop.br/).

Embora essa forma de cooperativismo exista no Brasil há cerca de 116 anos, foi somente nos últimos anos que ganhou destaque e vem crescendo a cada dia, a Cooperativa Sicredi foi elencada sete anos consecutivos como uma das melhores empresas para se trabalhar de acordo com a pesquisa realizada pela Revista 
Exame/Você S/A, na última edição (2018) foi eleita a melhor empresa no ramo em que atua.

As cooperativas possuem uma legislação especifica, a lei que define a Política Nacional de Cooperativismo é a Lei 5.764/1971, essa lei trata de características importantes das cooperativas e institui seu regime jurídico. O sistema OCB traz as normas e legislações que devem ser seguidas pelas cooperativas. Dentre outros normativos, leis e resoluções está a Resolução CFC 920/2001 - Aspectos contábeis de entidades cooperativas, a Resolução CFC 944/2002 - Entidades Cooperativas de Assistência à Saúde e a Resolução CFC 1.013/2005 - Entidades Cooperativas.

Essas resoluções tratavam das normas brasileiras de contabilidade e de algumas características contábeis especificas das cooperativas, porém foram revogadas pela Resolução 2017/ITG2004 que foi publicada em 29 de novembro de 2017 e entrou em vigor a partir do primeiro dia do mês de janeiro de 2018.

De acordo com o item três dessa resolução, a entidade cooperativa é aquela que exerce atividades na forma de lei específica, por meio de atos cooperativos, estão caracterizados pela prestação de serviços e não possuem como desejo principal o lucro, estão empenhadas em desenvolver tais atividades para obter um resultado melhor em comum para cada um dos seus cooperados.

Santos et al. (2012) evidenciam que os objetivos principais da contabilidade nas sociedades cooperativas são primeiramente prestar contas dos atos econômicos, mediante apresentação da documentação pertinente. Controlar os bens existentes e as movimentações que ocorrerem durante o exercício. Demonstrar a situação patrimonial e os indicadores de gestão da sociedade, apresentando como estão sendo geridos os recursos disponíveis além de demonstrar periodicamente os resultados específicos das atividades desenvolvidas e apresentar como foram realizadas e cumpridas as atividades sociais em cada período. 


\subsection{Satisfação No Trabalho}

Satisfação pode ser considerado um sentimento agradável, resultante da percepção de que o trabalho realizado promove a realização de valores importantes relacionado ao próprio trabalho. Locke (1976, citado por, Wagner e Hollenbeck, 2002) defende que a satisfação pode ser identificada por três elementos: valores que a pessoa almeja ter, a importância dada ao trabalho e a percepção da situação real da empresa em relação àquilo que o colaborador acredita.

Já para Martins (2010), a satisfação no trabalho está associada com a infraestrutura, benefícios, remuneração, chefia, capacitação técnica, relacionamento, oportunidade de crescimento interno e apreciação da realização pessoal. Kannane (2000) complementa que a satisfação está associada com algumas condições de vida no trabalho, como compensação adequada e clara, ambiente saudável e seguro, crescimento, autenticidade, relevância social, entre outros.

Não basta existir um ambiente favorável se não houver engajamento dos colaboradores. A consultoria Towers Watson e Willis (2014) apresenta três fatores que podem influenciar o desempenho da organização, sendo que eles se relacionam e se completam. De acordo com a pesquisa realizada, a consultoria trouxe como primeiro fator o suporte organizacional, proporcionando condições para realização das tarefas de modo eficiente e eficaz, em segundo lugar ficou o ambiente de trabalho, pois é necessário que o ambiente possua condições físicas e sociais favoráveis e que estimulem o colaborador, e o terceiro fator, talvez o mais importante, o engajamento do funcionário, combinando esses três fatores a empresa já possui condições para se manter viva e competitiva.

Levando-se em consideração esses três fatores pode-se desenhar uma estratégia que beneficie não somente a empresa na busca incessante de lucros, mas que proporcione desejo por parte dos colaboradores em fazer parte da equipe e 
superar as metas. A busca constante por melhores resultados faz com que várias empresas utilizem como estratégia organizacional boa relação com seus empregados como um dos fatores para o aumento da produtividade, crescimento e aumento da vantagem competitiva (LIMA; CORRAR, 2010).

É impossível fazer a diferença no mundo dos negócios senão houver pessoas motivadas e que estejam realmente dispostas a trabalhar e conquistar as vitórias junto com a sua empresa, para Meinen e Port (2012), é preciso que exista um ambiente que seja capaz de acolher seus colaboradores e que possua ao mesmo tempo políticas e benefícios que sejam capazes de valorizar o conhecimento individual e que incentivem o desenvolvimento e a capacitação profissional e pessoal. Isso está relacionado com a forma que o funcionário consegue ver suas responsabilidades e o quanto é importante para equipe o seu comprometimento, caso contrário o funcionário poderá ficar desmotivado, deixando assim de contribuir para o objetivo empresarial.

Embora haja um bom relacionamento entre a equipe, não significa que todos os colaboradores estejam plenamente satisfeitos. É necessário implementar vantagens e garantias reais de crescimento profissional que motive a busca por aperfeiçoamento e desenvolvimento pessoal. Hedler e Castro (2015), relatam que as organizações devem possuir um plano de carreira bem definido, que seja suficientemente bom, que satisfaça e mantenha seus funcionários motivados. Além dos atributos necessários para motivar seus funcionários, as empresas devem investir em políticas que retenham seus talentos, devem investir em políticas que agreguem valores para a equipe.

Oliveira et al. (2012) afirmam que o desempenho dos funcionários pode ser melhorado quando o ambiente é receptível e amigável, segundo o autor esses fatores afetam os colabores de forma positiva gerando segurança para tomar decisões e expor suas ideias, porém a reciproca é verdadeira, pois quando se está em um 
ambiente de cobrança extrema e sem confiança, acaba gerando estres e desmotivação afetando diretamente o resultado.

Niceletti, Fabricio e Carneiro (2018) utilizaram a Escala de Satisfação no Trabalho, proposta por Siqueira (2008) com o objetivo de é identificar e analisar a satisfação dos funcionários de Instituição Financeira Cooperativa. Por meio da opinião de 37 colaboradores, os autores concluíram que a dimensão "Chefia" recebeu a maior nota, seguida pela dimensão de relacionamento com os colegas, já a dimensão "Salários", obteve o menor índice de satisfação.

Goulart et al (2017) desenvolveram uma análise entre os indicadores de Recursos Humanos - Rotatividade, Absenteísmo e Remuneração Variável e os indicadores Econômico Financeiros - faturamento e sobras - de empresas cooperativas no Paraná. Os resultados mostram que os indicadores de recursos humanos apresentam alta variabilidade, mas possuem baixa relação com os indicadores de desempenho econômico financeiro.

\section{PROCEDIMENTO METODOLÓGICO}

Esse estudo é descritivo quanto à natureza do objetivo e tem-se uma pesquisa quantitativa quanto à abordagem do problema. No que tange a estratégia de pesquisa tem-se a pesquisa de campo por meio da aplicação de questionários.

Gil (1999, p.128), define questionário “como a técnica de investigação composta por um número mais ou menos elevado de questões apresentadas por escrito às pessoas, tendo por objetivo o conhecimento de opiniões, crenças, sentimentos, interesses, expectativas, situações vivenciadas etc.". Essa forma de coleta de dados foi escolhida por permitir captar um vasto conjunto de informações e mante o anonimato das pessoas envolvidas. 
A população escolhida para aplicação do questionário foram os colaboradores de uma Cooperativa de crédito na região Centro-Oeste do Paraná, da qual foi retirada uma amostra para poder analisar os dados, a qual foi formada por adesão, não sendo, portanto, probabilística. Noé (2017) define a amostra como uma fração da população estudada, de acordo com o autor é impossível aplicar a entrevista para todos os elementos da população, sendo necessários determinar um número satisfatório e que represente o pensamento dessa população.

Os questionários foram enviados via malote para as 12 unidades de atendimento que compõe a respectiva empresa estudada. Os colaboradores responderam as perguntas de forma manual e sem identificação, portanto, de forma anônima. Em seguida os dados foram tabulados e analisados utilizando a ferramenta Excel e SPSS. Os questionários que apresentaram mais de $70 \%$ das respostas na mesma nota foram eliminados da amostra.

Para verificar se existe relação entre a Satisfação no Trabalho e o resultado atingido pela empresa foi utilizado o teste de correlação de Spearman. Ainda que o teste de correlação de Pearson seja mais robusto, não foi possível a sua utilização pois o estudo é composto de apenas 12 observações.

\subsection{Escala de Satisfação no Trabalho}

Para avaliar a satisfação dos colaboradores Siqueira (2008) propõe um instrumento denominado de Escala de Satisfação no Trabalho, composta de 25 questões, as quais abordam cinco dimensões de satisfação: Relação com colegas, Salário, Natureza do Trabalho, Chefia e Promoções.

Para Siqueira (2008), dentro da pesquisa de clima organizacional, as unidades de medidas podem ser os indivíduos ou até mesmo pequenos grupos de trabalhos. 
Nessa pesquisa foi avaliado se o comportamento e o relacionamento entre os colegas de trabalhos e seus superiores tem relação com o resultado contábil da instituição.

O questionário aplicado segue o modelo proposto por Siqueira (2008) e teve como objetivo identificar quantitativamente nível de satisfação dos colaboradores foi aplicado o questionário, cujas questões estão disponíveis no Quadro 1. Os participantes deram uma nota entre 1 e 7 para cada uma das questões, onde a nota de 1 a 3 vai de muito insatisfeito até insatisfeito, nota 4 indica que o quesito é indiferente, seria o equilíbrio entre estar satisfeito ou insatisfeito e por fim, as notas de 5 a 7 correspondem de satisfeito até muito satisfeito.

Quadro 1: Questões sobre satisfação no trabalho de acordo com Siqueira (2008)

\begin{tabular}{|c|c|}
\hline Satisfação com: & No seu trabalho atual você sente... \\
\hline \multirow{5}{*}{ Colegas de Trabalho } & (7) Ao espírito de colaboração dos seus colegas de trabalho. \\
\hline & (12) Ao tipo de amizade que os seus colegas demonstram por você. \\
\hline & (20) A maneira como se relaciona com os seus colegas de trabalho. \\
\hline & (23) A quantidade de amigos que tem entre seus colegas de trabalho. \\
\hline & A confiança que você pode ter em seus colegas de trabalho. \\
\hline \multirow{5}{*}{ Salário } & (11) Ao seu salário comparado com o quanto você trabalha. \\
\hline & (14) Ao seu salário comparado à sua capacidade profissional. \\
\hline & (18) Ao seu salário comparado ao custo de vida. \\
\hline & (21) A quantia em dinheiro que recebe desta empresa ao final de cada mês. \\
\hline & (27) Ao seu salário comparado aos seus esforços no trabalho. \\
\hline \multirow{5}{*}{ Chefia } & (8) Ao modo como seu chefe organiza o trabalho do seu setor. \\
\hline & (15) Ao interesse de seu chefe pelo seu trabalho. \\
\hline & (25) Ao entendimento entre você e seu chefe. \\
\hline & (28) A maneira como seu chefe te trata. \\
\hline & (31) A capacidade profissional de seu chefe. \\
\hline \multirow{5}{*}{ Natureza do Trabalho } & (13) Ao grau de interesse que as suas atividades Ihe despertam. \\
\hline & (17) A capacidade de seu trabalho te absorver. \\
\hline & (19) A oportunidade de fazer o tipo de trabalho que faz. \\
\hline & (24) As preocupações exigidas pelo seu trabalho. \\
\hline & (29) A variedade de tarefas que você realiza. \\
\hline \multirow{2}{*}{ Promoções } & (9) Ao número de vezes que já foi promovido nesta empresa. \\
\hline & (10) As garantias que a empresa oferece a quem é promovido. \\
\hline
\end{tabular}


(16) A maneira como esta empresa promove de seu pessoal.

(22) As oportunidades de ser promovido nesta empresa.

(26) Ao tempo que tem de esperar para ser promovido nesta empresa.

Fonte: Siqueira (2008)

Os números que aparecem ao lado das questões representam a ordem em que as perguntas aparecem no questionário. Nesse sentido, as questões que representam cada constructo foram separadas, evitando influenciar o respondente.

\section{RESULTADOS}

\subsection{Características da Empresa e Perfil do Respondente}

Este estudo foi realizado em uma cooperativa de crédito localizada na região Centro-oeste do estado do Paraná, que possui trinta e cinco anos de história e pertence ao sistema Sicredi que foi considerado nos últimos sete anos uma das melhores empresas para se trabalhar segundo a revista Exame/Você S/A (2018).

A empresa estudada foi constituída em 10 de agosto de 1983, por 32 sócios fundadores. Desde então vem crescendo e mantendo seu desejo vivo. No início seu principal desejo era atender a necessidade de recursos para a realização das atividades rurais. Em 1992 passou a fazer parte Sistema de Crédito Cooperativo SICREDI. No ano de 2011, se tornou uma cooperativa de livre admissão, o que possibilitava que qualquer pessoa física ou jurídica pudesse utilizar os serviços prestados pela cooperativa (SICREDI, 2018).

Dos 163 questionários enviados por e-mail, obteve-se retorno e 115, porém 10 foram descartados por conterem mais de $70 \%$ das respostas na mesma nota, e 3 por conterem várias respostas em branco, restando 102 respostas válidas, restando 102 respostas válidas, distribuídas nas 11 agências da cooperativa e a Superintendência 
Regional (SUREG), que serão identificados apenas por uma letra $A$ a $L$ para preservar suas identidades, culminando em uma amostra que corresponde a $62,58 \%$ da população investigada, como demonstrado na Tabela 1.

Tabela1: Número de respostas por agência

\begin{tabular}{l|l|l|l}
\hline Agência que atua & Total de Colaboradores & Respondentes & \% da população \\
\hline A & 11 & 7 & 63,63 \\
\hline B & 7 & 5 & 71,43 \\
\hline C & 20 & 10 & 50 \\
\hline D & 16 & 6 & 37,5 \\
\hline E & 11 & 6 & 54,54 \\
\hline F & 10 & 7 & 70 \\
\hline G & 10 & 6 & 60 \\
\hline H & 13 & 6 & 46,15 \\
\hline I & 8 & 6 & 75 \\
\hline J & 7 & 6 & 85,71 \\
\hline K & 9 & 6 & 66,67 \\
\hline L & 41 & 31 & 73,80 \\
\hline Total & 163 & 102 & 62,58 \\
\hline
\end{tabular}

Fonte: Elaborado pelo autor

Nota-se que em todas unidades envolvidas no estudo, $50 \%$ ou mais dos colaboradores se dispuseram a participar da pesquisa respondendo o questionário, compondo uma amostra que representa aproximadamente $63 \%$ do quadro de funcionários.

A Tabela 2 permite conhecer um pouco do perfil dos respondentes, especificamente quanto ao tempo de atuação na empresa e a área de formação dos participantes. Observa-se que o volume de colaboradores com até um ano de empresa representa a maior parte da amostra (25,49\%), o que pode representar o crescimento da organização pela contratação de mais colaboradores no último ano, 
como também pode ser um efeito de rotatividade, elemento que não é investigado nesse estudo. Por outro lado, observa-se que a segunda maior participação (23,53\%) é de colaboradores que estão na organização a mais de 5 anos. Percebe-se que a instituição valoriza seus colaboradores e procura manter seus talentos, possuindo um total de $29,41 \%$ de colaboradores de dois a cinco anos e $23,53 \%$ de colaboradores com mais de cinco anos de serviço na instituição.

Tabela 2: Área de formação e tempo de serviço na empresa

\begin{tabular}{|c|c|c|c|c|c|}
\hline $\begin{array}{l}\text { Tempo de } \\
\text { Serviço }\end{array}$ & $\begin{array}{l}\mathbf{N}^{\circ} \\
\text { colaboradore } \\
\text { S }\end{array}$ & $\%$ & Curso de formação & $\begin{array}{l}\mathbf{N}^{\circ} \\
\text { colaboradores }\end{array}$ & $\%$ \\
\hline Até 1 ano & 26 & 25,49 & Administração & 62 & 60,78 \\
\hline De 1 a 2 anos & 22 & 21,57 & Ciências Contábeis & 15 & 14,71 \\
\hline De 2 a 3 anos & 15 & 14,71 & $\begin{array}{l}\text { Ciências } \\
\text { Econômicas }\end{array}$ & 13 & 12,75 \\
\hline De 3 a 4 anos & 8 & 7,84 & $\begin{array}{l}\text { Sistemas de } \\
\text { Informação }\end{array}$ & 4 & 3,92 \\
\hline De 4 a 5 anos & 7 & 6,86 & Direito & 3 & 2,94 \\
\hline Acima de 5 anos & 24 & 23,53 & Outros & 5 & 4,90 \\
\hline TOTAL & 102 & 100,00 & TOTAL & 102 & $\begin{array}{l}100,0 \\
0\end{array}$ \\
\hline
\end{tabular}

Fonte: Dados da pesquisa

No que se refere a área de formação, a pesquisa apresenta o curso concluído ou em andamento dos entrevistados. O estudo indica que todos os participantes já possuem nível superior ou estão cursando. Quanto ao curso superior, tem-se que a grande maioria os profissionais têm formação na área de Sociais Aplicadas, representados principalmente por Administração, Contabilidade e Economia, cursos ligados à área de negócios e finanças e, portanto, compatível com o tipo de serviço prestado pela empresa objeto de estudo. Os outros cursos, que representam 
aproximadamente 12\% da amostra, são de Sistema de Informação, Direito, Secretariado Executivo, Gestão Comercial e Recursos Humanos.

\subsection{Satisfação Geral no Trabalho}

Para avaliar o nível de satisfação no trabalho foi utilizada a Escala de Satisfação no Trabalho - EST, proposta por Siqueira (2008). A escala investiga a satisfação do colaborador em 5 dimensões distintas: Relação com colegas, Salário, Natureza do Trabalho, Chefia e Promoções. A Tabela 3 demonstra o nível de satisfação da empresa como um todo, cujos resultados estão apresentados pelas dimensões sugeridas por Siqueira (2008).

Tabela 3: Satisfação geral dos trabalhadores quanto ao Relacionamento com os Colegas

\begin{tabular}{|c|c|c|c|c|c|c|c|}
\hline Questões/Notas & 1 & 2 & 3 & 4 & 5 & 6 & 7 \\
\hline $\begin{array}{l}\text { Ao espírito de colaboração } \\
\text { dos seus colegas de trabalho. }\end{array}$ & - & - & $1,96 \%$ & $4,90 \%$ & $25,49 \%$ & $35,29 \%$ & $32,35 \%$ \\
\hline $\begin{array}{l}\text { Ao tipo de amizade que os } \\
\text { seus colegas demonstram } \\
\text { por você. }\end{array}$ & - & $0,98 \%$ & $3,92 \%$ & $5,88 \%$ & $18,63 \%$ & $33,33 \%$ & $37,25 \%$ \\
\hline $\begin{array}{l}\text { A maneira como se relaciona } \\
\text { com os seus colegas de } \\
\text { trabalho. }\end{array}$ & $0,98 \%$ & - & - & $1,96 \%$ & $12,75 \%$ & $36,27 \%$ & $48,04 \%$ \\
\hline $\begin{array}{l}\text { A quantidade de amigos que } \\
\text { tem entre seus colegas de } \\
\text { trabalho. }\end{array}$ & $5,88 \%$ & $3,92 \%$ & $5,88 \%$ & $7,84 \%$ & $25,49 \%$ & $27,45 \%$ & $23,53 \%$ \\
\hline $\begin{array}{l}\text { A confiança que você pode } \\
\text { ter em seus colegas de } \\
\text { trabalho. }\end{array}$ & $0,98 \%$ & $0,98 \%$ & $0,98 \%$ & $12,75 \%$ & $25,49 \%$ & $39,22 \%$ & $19,61 \%$ \\
\hline Relação com os colegas & $1,57 \%$ & $1,18 \%$ & $2,55 \%$ & $6,67 \%$ & $21,57 \%$ & $34,31 \%$ & $32,16 \%$ \\
\hline
\end{tabular}

Fonte: Dados da pesquisa 
Quanto ao Relacionamento com Colegas, cujas perguntas estão relacionadas com a colaboração, tipo de amizade e confiança mútua, os resultados demonstram que $66,47 \%$ dos trabalhadores estão satisfeitos ou muito satisfeitos com o relacionamento com colegas, pois atribuíram nota entre 6 e 7. Destaca-se que o maior volume de respostas $(34,31 \%)$ está concentrado na nota 6 , demonstrando que ainda há o que ser feito nesse sentido na organização, de modo que o colaborador se sinta totalmente satisfeito com o relacionamento com os colegas de trabalho. Mas, de modo geral, a percepção dos colaboradores em relação ao entrosamento da equipe e o comprometimento dos colegas de trabalho, apresentaram igualmente um alto índice de satisfação, a organização possui um ótimo relacionamento entre os colaboradores o que pode justificar os resultados obtidos nos últimos anos.

Tabela 4: Satisfação geral dos trabalhadores quanto ao Salário

\begin{tabular}{|c|c|c|c|c|c|c|c|}
\hline Questões/Notas & 1 & 2 & 3 & 4 & 5 & 6 & 7 \\
\hline $\begin{array}{l}\text { Ao seu salário comparado com } \\
\text { o quanto você trabalha. }\end{array}$ & $0,98 \%$ & $2,94 \%$ & $4,90 \%$ & $14,71 \%$ & $29,41 \%$ & $36,27 \%$ & $10,78 \%$ \\
\hline $\begin{array}{l}\text { Ao seu salário comparado à } \\
\text { sua capacidade profissional. }\end{array}$ & $0,98 \%$ & - & $3,92 \%$ & $16,67 \%$ & $33,33 \%$ & $36,27 \%$ & $8,82 \%$ \\
\hline $\begin{array}{l}\text { Ao seu salário comparado ao } \\
\text { custo de vida. }\end{array}$ & $0,98 \%$ & $0,98 \%$ & $8,82 \%$ & $13,73 \%$ & $38,24 \%$ & $29,41 \%$ & $7,84 \%$ \\
\hline $\begin{array}{l}\text { A quantia em dinheiro que } \\
\text { recebe desta empresa ao final } \\
\text { de cada mês. }\end{array}$ & $0,98 \%$ & $1,96 \%$ & $0,98 \%$ & $11,76 \%$ & $43,14 \%$ & $29,41 \%$ & $11,76 \%$ \\
\hline $\begin{array}{l}\text { Ao seu salário comparado aos } \\
\text { seus esforços no trabalho. }\end{array}$ & $0,98 \%$ & - & $4,90 \%$ & $13,73 \%$ & $36,27 \%$ & $35,29 \%$ & $8,82 \%$ \\
\hline Salário & $0,98 \%$ & $1,18 \%$ & $4,70 \%$ & $14,12 \%$ & $36,08 \%$ & $33,33 \%$ & $9,60 \%$ \\
\hline
\end{tabular}

Fonte: Dados da pesquisa 
Quanto ao Salário é possível perceber que existe uma visão mais ampla sendo que em média apenas 9,60\% diz estar muito satisfeito, 33,33\% atribuíram a nota 6 e $36,08 \%$ atribuíram nota 5, que significa que os colaboradores estão satisfeitos, porém são necessárias melhorias com relação ao tipo de remuneração para que se obtenha um índice melhor de satisfação. Observa-se que 84,31\% dos entrevistados atribuíram nota 5,6 ou 7 quando questionado sobre a quantia de dinheiro que recebe ao final de cada mês, porém, quando questionado sobre o seu salário comparado com o custo de vida o índice caiu para 75,49\%, o que pode estar relacionado com fatores externos e que não dependem apenas da instituição, mas que podem ser levados em consideração para uma política de remuneração.

Tabela 5: Satisfação geral dos trabalhadores quanto a Chefia

\begin{tabular}{|c|c|c|c|c|c|c|c|}
\hline \multicolumn{8}{|l|}{ Chefia } \\
\hline Questões/Notas & 1 & 2 & 3 & 4 & 5 & 6 & 7 \\
\hline $\begin{array}{l}\text { Ao modo como seu gestor organiza } \\
\text { o trabalho do seu setor. }\end{array}$ & - & $0,98 \%$ & $0,98 \%$ & $4,90 \%$ & $20,59 \%$ & $31,37 \%$ & $41,18 \%$ \\
\hline $\begin{array}{l}\text { Ao interesse de seu gestor pelo seu } \\
\text { trabalho. }\end{array}$ & - & $0,98 \%$ & $1,96 \%$ & $0,00 \%$ & $22,55 \%$ & $35,29 \%$ & $39,22 \%$ \\
\hline $\begin{array}{l}\text { Ao entendimento entre você e seu } \\
\text { gestor. }\end{array}$ & $0,98 \%$ & - & - & $1,96 \%$ & $9,80 \%$ & $30,39 \%$ & $56,86 \%$ \\
\hline A maneira como seu gestor te trata. & $2,94 \%$ & - & $0,98 \%$ & $0,98 \%$ & $13,73 \%$ & $33,33 \%$ & $48,04 \%$ \\
\hline $\begin{array}{l}\text { A capacidade profissional de seu } \\
\text { gestor. }\end{array}$ & - & $0,98 \%$ & $0,98 \%$ & $4,90 \%$ & $7,84 \%$ & $26,47 \%$ & $58,82 \%$ \\
\hline Chefia & $0,78 \%$ & $0,58 \%$ & $0,98 \%$ & $2,54 \%$ & $14,90 \%$ & $31,37 \%$ & $48,82 \%$ \\
\hline
\end{tabular}

Fonte: Dados da pesquisa

Quanto a Chefia, têm se um alto índice de satisfação sendo que em média 48,82\% estão muito satisfeitos e atribuíram nota máxima, esse alto índice está relacionado principalmente com a capacidade profissional dos gestores $(58,82 \%)$ e 0 entendimento entre colaborador e gestor $(56,86 \%)$, seguido por uma média de $31,37 \%$ com nota 6 , totalizando uma média de $80,19 \%$ dos entrevistados como satisfeitos ou muito satisfeitos. É possível perceber a preocupação que a organização possui quanto a formação dos seus gestores, uma vez que 93,13\% dos entrevistados 
dizem estar satisfeito ou muito satisfeito em relação a capacidade profissional dos seus gestores, em contra partida temos um alto índice de preocupação dos gestores em relação ao trabalho realizado pelos funcionários, apresentando um índice de 97,06\% com notas de 5 a 7 que indica que os colaboradores estão satisfeitos ou muito satisfeito com a forma que seus gestores demonstram essa preocupação, o que acaba gerando um maior comprometimento na equipe, e se transforma em resultados para a empresa. Também é visível que o alto índice de investimento na formação dos gestores se traduz em uma melhor organização das tarefas diárias, que satisfaz as expectativas geradas pelos colaboradores. Essa organização de tarefas é parte da eficácia necessária para a obtenção dos melhores resultados utilizando-se das mesmas ferramentas disponíveis, para isso é necessário que o gestor conheça sua equipe e seja capaz de criar motivação para que todos se engajem nas metas propostas.

Tabela 6: Satisfação geral dos trabalhadores quanto a Natureza do Trabalho

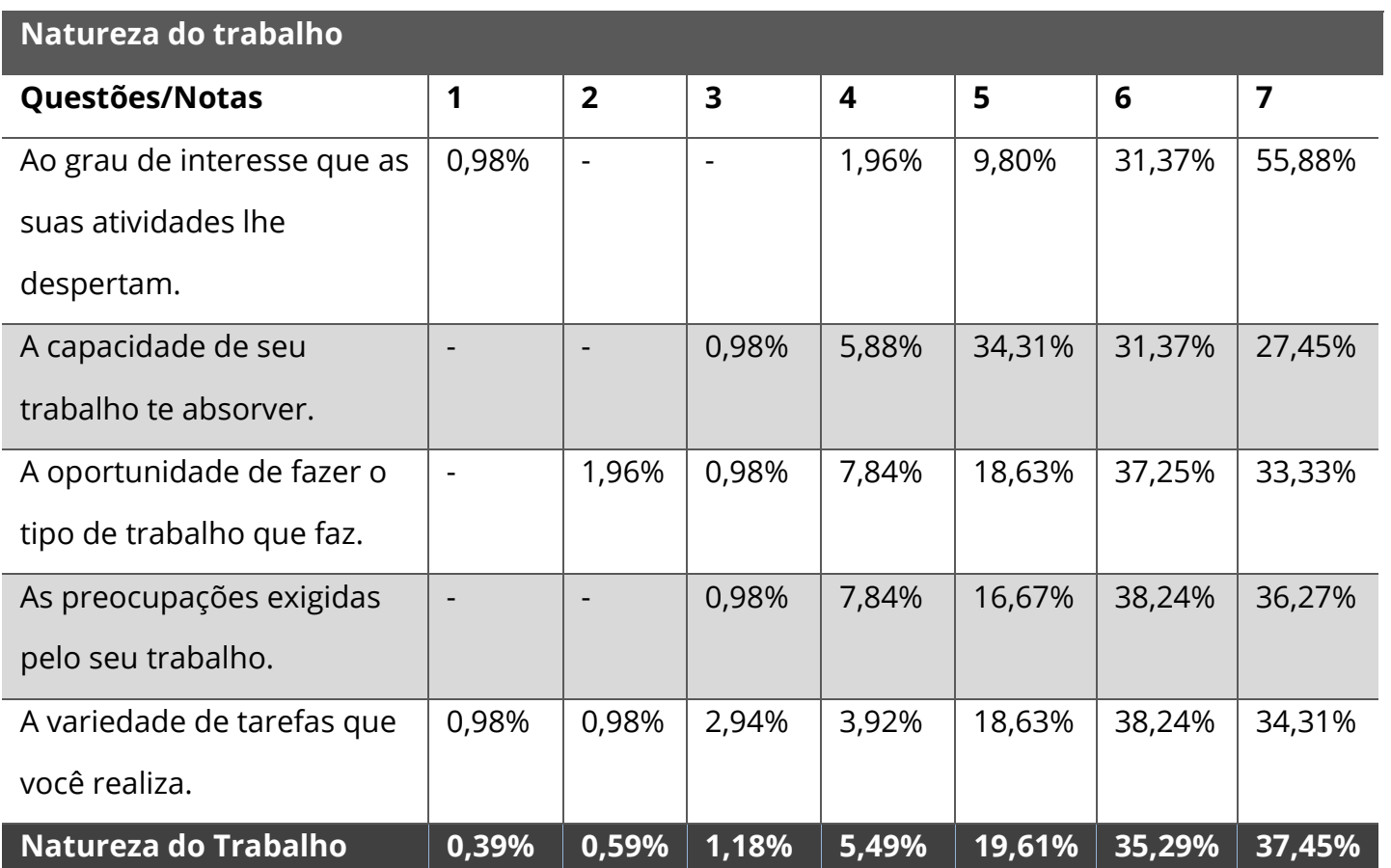

Fonte: Dados da pesquisa 
Quanto a Natureza do Trabalho 55,88\% dos entrevistados dizem estar muito satisfeitos em relação ao grau de interesse que as atividades lhes despertam, porém as médias nesse grupo ficaram divididas em $37,45 \%$ de colaboradores muito satisfeitos, 35,29\% com nota 6 e a terceira maior média com 19,61\% referente a nota 5, o que significa que apesar da equipe estar bem entrosada é preciso criar novos desafios, para que os colaboradores possam colocar em pratica seus aprendizados, pois trata-se de uma equipe onde todos possuem alguma formação acadêmica ou estão cursando. Ao serem questionados sobre a capacidade de absorção de seu trabalho, 34,31\% designaram a nota 5 representando por tanto, que estão satisfeitos, porém é preciso criar uma forma de gerar um maior comprometimento do colaborador em relação ao seu trabalho realizado. Observando-se de forma geral as médias obtidas nesse grupo, é possível identificar que os colaboradores desejam realizar mais atividades diferenciadas, onde possam ter responsabilidades condizentes com sua capacidade.

Tabela 7: Satisfação geral dos trabalhadores quanto a Promoção

\begin{tabular}{|c|c|c|c|c|c|c|c|}
\hline \multicolumn{8}{|l|}{ Promoção } \\
\hline Questões/Notas & 1 & 2 & 3 & 4 & 5 & 6 & 7 \\
\hline $\begin{array}{l}\text { Ao número de } \\
\text { vezes que já foi } \\
\text { promovido nesta } \\
\text { empresa. }\end{array}$ & $44,12 \%$ & $7,84 \%$ & $8,82 \%$ & $11,76 \%$ & $5,88 \%$ & $10,78 \%$ & $10,78 \%$ \\
\hline $\begin{array}{l}\text { As garantias que } \\
\text { a empresa } \\
\text { oferece a quem é } \\
\text { promovido. }\end{array}$ & $5,88 \%$ & $2,94 \%$ & $4,90 \%$ & $20,59 \%$ & $11,76 \%$ & $29,41 \%$ & $24,51 \%$ \\
\hline $\begin{array}{l}\text { A maneira como } \\
\text { esta empresa } \\
\text { promove de seu } \\
\text { pessoal. }\end{array}$ & $1,96 \%$ & - & $1,96 \%$ & $13,73 \%$ & $26,47 \%$ & $24,51 \%$ & $31,37 \%$ \\
\hline
\end{tabular}




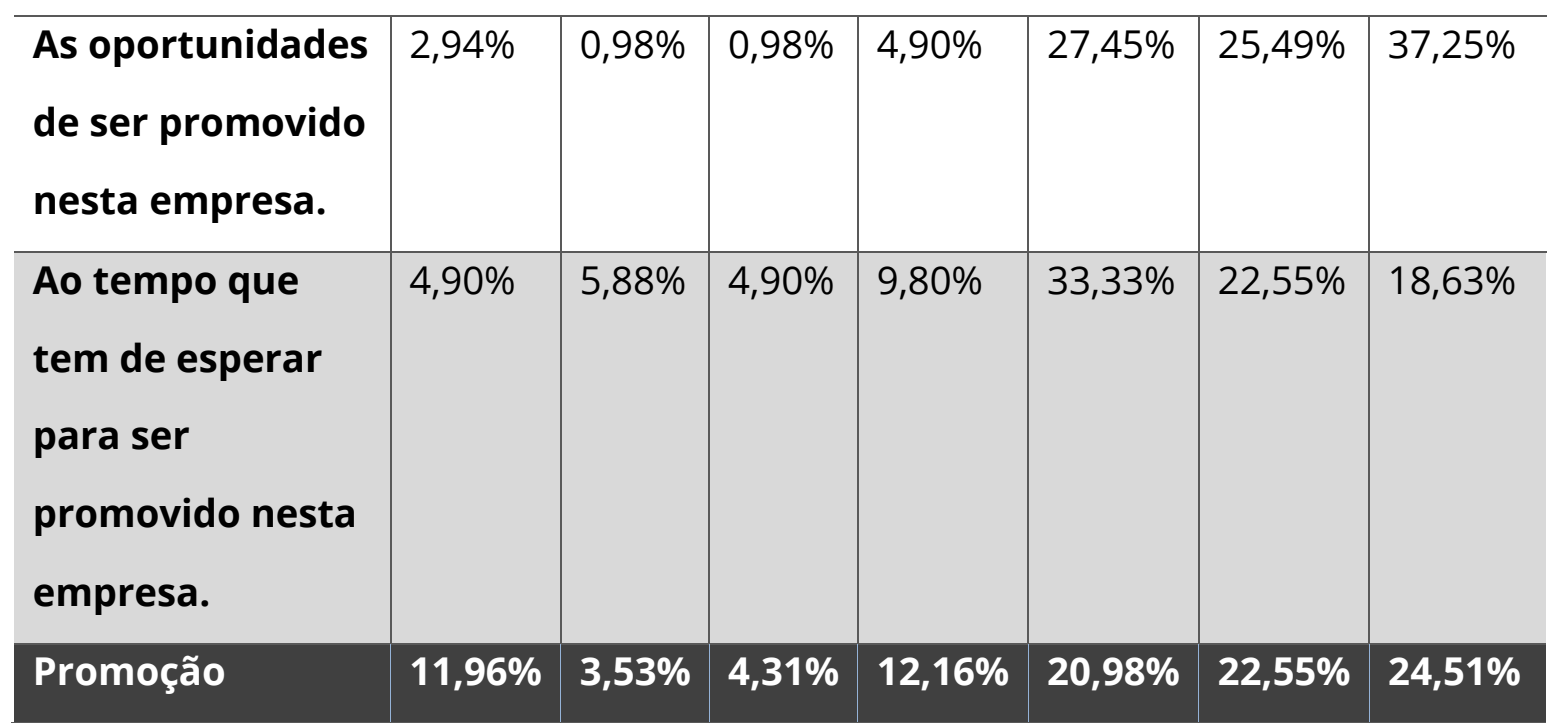

Fonte: Dados da pesquisa

Quanto as Promoções, obteve-se a maior média de insatisfação onde 44,12\% dos entrevistados diz estar muito insatisfeito com o número de vezes em que foi promovido, o que pode ser explicado pelo número de colaboradores com menos de 2 anos de serviço, que indica que a empresa investigada possui um período de maturação dos seus colaboradores, necessário para desenvolver algumas capacidades primordiais para o desenvolvimento de outras atividades. Apesar de existir um grande índice de insatisfação com a quantidade de vezes que o colaborador foi promovido, a empresa gera uma grande expectativa de crescimento, incentivando o desenvolvimento profissional pois $84,31 \%$ dos entrevistados estão satisfeitos ou muito satisfeitos com as oportunidades que a empresa apresenta. Apesar do grupo apresentar um índice maior de insatisfação comparado com os outros grupos, obteve-se em média $24,51 \%$ de colaboradores com nota 7 e do outro lado obteve-se $11,96 \%$ com nota 1 , indicando portanto a necessidade de se trabalhar melhor a forma de promoção dos colaborados, também pode ser analisado a forma como está sendo contratado os colaboradores para poder identificar qual a causa do número de pessoas contratadas com menos de 1 anos e identificar possíveis falhas na contratação de colaboradores que não atendem as expectativas da empresa e acabam se frustrando e desmotivando a equipe. 
Tabela 8: Satisfação geral dos trabalhadores

\begin{tabular}{l|l|l|l|l|l|l|l}
\hline Notas & $\mathbf{1}$ & $\mathbf{2}$ & $\mathbf{3}$ & $\mathbf{4}$ & $\mathbf{5}$ & $\mathbf{6}$ & $\mathbf{7}$ \\
\hline \multirow{3}{*}{ GERAL } & $3,14 \%$ & $1,41 \%$ & $2,74 \%$ & $8,20 \%$ & $22,63 \%$ & $31,37 \%$ & $30,51 \%$ \\
\cline { 2 - 7 } & $\begin{array}{l}\mathbf{7 , 2 9} \% \\
\text { Insatisfeito }\end{array}$ & $\begin{array}{l}\mathbf{8 , 2 0 \%} \\
\text { Indiferente }\end{array}$ & $\begin{array}{l}\mathbf{8 4 , 5 1 \%} \\
\text { Satisfeitos }\end{array}$ \\
\hline
\end{tabular}

Fonte: Dados da pesquisa

Ao analisar o resultado geral quanto a satisfação dos trabalhadores investigados, nota-se que a grande maioria dos participantes - 84,51\% - concentraram, em média, suas notas entre 5 e 7, indicando estarem satisfeitos com o trabalho. Para aproximadamente $8 \%$ dos respondentes, a opinião quanto a satisfação é indiferente, pois posicionaram sua nota em 4. E para a menor parte, em torno de 7\%, não há satisfação no trabalho. O resultado mostra que o modelo de gestão de pessoas utilizado na empresa investigada permite com que o colaborador se sinta satisfeito no trabalho.

\subsection{Satisfação No Trabalho Por Agência}

Na Tabela 9 está apresentado o resultado do estudo separado por agência investigada, visando identificar se as médias de cada constructo variam de forma relevante entre elas.

Tabela 9: Satisfação no Trabalho por Agência

\begin{tabular}{l|l|l|l|l|l|l|l|l|l|l|l|l}
$\begin{array}{l}\text { Agência } \\
\text { Dimensão }\end{array}$ & A & B & C & D & E & F & G & H & I & J & K & L \\
\hline $\begin{array}{l}\text { Relação } \\
\text { com }\end{array}$ & 6,2 & 6,4 & 5,9 & 5,5 & 5,27 & 5,5 & 6,2 & 5,8 & 5,90 & 5,8 & 5,9 & 5,51 \\
colegas & 0 & 4 & 6 & 7 & & 1 & 7 & 7 & & 0 & 3 & \\
\hline Salário & 5,9 & 4,6 & 4,9 & 4,7 & 5,5 & 5,6 & 5,83 & 5,5 & 4,93 & 5,6 & 5,0 & 5,00 \\
\hline
\end{tabular}




\begin{tabular}{l|l|l|l|l|l|l|l|l|l|l|l|l}
\hline & 1 & 8 & 4 & 0 & 3 & 9 & & 3 & & 7 & 0 & \\
\hline Chefia & 6,0 & 6,8 & 6,3 & 5,7 & 6,0 & 5,8 & 5,80 & 6,3 & 6,37 & 6,3 & 6,5 & 6,21 \\
\hline $\begin{array}{l}\text { Natureza } \\
\text { do }\end{array}$ & $\begin{array}{l}5 \\
\text { Trabalho }\end{array}$ & 4 & 6 & 3 & 0 & 3 & & 3 & & 7 & 0 & \\
\hline $\begin{array}{l}\text { Promoçõe } \\
\text { s }\end{array}$ & 4,71 & 5,48 & 4,66 & 4,73 & 5,27 & 4,86 & 4,97 & 5,37 & 5,53 & 5,13 & 4,73 & 4,63 \\
\hline
\end{tabular}

Fonte: Dados da pesquisa

As notas apresentadas na Tabela 9 representam a média obtida em cada dimensão pesquisada, distribuídas por agência. Para o cálculo das médias foi realizado a soma das notas obtidas em cada questão e dividido pelo número de respondentes de cada agência.

Observa-se que todas as notas médias estão acima de 4 pontos, o que demonstra que a satisfação dos colaboradores está acima do ponto médio e tende a satisfação plena, porém ainda existe margem para melhorias e que são de grande importância para a superação dos resultados desejados.

As melhores notas são em relação a Natureza do trabalho, Chefia e a Relação com os colegas, todas as médias estão acima de 5 pontos, isso se deve a harmonia e sintonia dos colaboradores, indicando uma cooperação e satisfação mutua, alinhada com os objetivos, confirmando a hipótese de que para uma produção satisfatória os colaboradores devem estar satisfeitos com as condições de trabalho, sendo elas físicas ou sociais, envolvendo o relacionamento profissional e social dos trabalhadores. 
4.4Satisfação no Trabalho versus Resultado Contábil

Na sequência, na Tabela 10 estão apresentadas as notas médias obtidas por agência confrontando com o resultado contábil do ano de 2018, para obtenção das médias por agência foi realizado a soma das notas obtidas em cada segmento e dividido por 5, que representa o número de segmentos trabalhados na Escala de Satisfação no Trabalho.

Tabela 10: Satisfação no Trabalho Versus Resultado Contábil por Agência

\begin{tabular}{|c|c|c|c|c|c|c|}
\hline $\begin{array}{l}\text { Agência } \\
\text { Dimensão }\end{array}$ & $\mathbf{A}$ & B & C & D & E & $\mathbf{F}$ \\
\hline Satisfação no trabalho & 5,68 & 5,98 & 5,56 & 5,27 & 5,65 & 5,60 \\
\hline Resultado contábil & $\begin{array}{l}1.953 .5 \\
19\end{array}$ & 106.943 & $\begin{array}{l}2.796 .8 \\
82\end{array}$ & $\begin{array}{l}1.668 .1 \\
41\end{array}$ & $\begin{array}{l}2.227 .0 \\
03\end{array}$ & -58.312 \\
\hline $\begin{array}{l}\text { Agência } \\
\text { ]Dimensão }\end{array}$ & G & H & I & $J$ & $\mathbf{K}$ & L \\
\hline Satisfação no trabalho & 5,84 & 5,84 & 5,75 & 5,82 & 5,68 & 5,44 \\
\hline Resultado contábil & 169.131 & $\begin{array}{l}2.152 .34 \\
3\end{array}$ & 872.336 & 30.038 & 599.512 & 11.318 .516 \\
\hline
\end{tabular}

Fonte: Dados da pesquisa

Todas as médias ficaram acima de 5 pontos, indicando que, independente do resultado contábil obtido em cada unidade, o índice de satisfação manteve-se acima da nota 5, demonstrando que mesmo nos casos onde o resultado contábil é negativo, nas unidades K e F, o colaborador afirma estar satisfeito com o trabalho. Destaca-se que nestas unidades, especificamente, tem pouco tempo de atuação e ainda se encontram em fase de maturação e viabilização. Nessa fase é comum o resultado ser negativo. 
O resultado global no valor de 11,3 milhões confirma o crescimento da instituição, e está alinhado com a satisfação apresentada por seus colaboradores que possui 5,68 pontos de média geral, sendo considerado um clima organizacional satisfatório. Também é possível perceber que os colaboradores estão atuando de maneira satisfatória e que estão comprometidos com os valores e objetivos da empresa, buscando a realização pessoal e profissional.

Com intuito de verificar se a satisfação no trabalho, considerando as dimensões, está correlacionado com o resultado obtido. Para tanto, os resultados foram submetidos ao Teste de Correlação de Spearman. O teste de Spearman foi escolhido pelo fato do estudo ser formado por somente 12 observações, impossibilitando o uso do teste de Pearson. O resultado do teste está disponível na Tabela 11.

Tabela 11: Correlação entre as dimensões de satisfação e resultado contábil

\section{Correlações Rô de Spearman Rô de Spearman}

\begin{tabular}{|c|c|c|c|c|c|c|}
\hline & & $\begin{array}{l}\text { Relação } \\
\text { com } \\
\text { colegas }\end{array}$ & Salário & Chefia & $\begin{array}{l}\text { Natureza } \\
\text { do } \\
\text { Trabalho }\end{array}$ & Promoções \\
\hline \multirow[t]{3}{*}{ Salário } & Correlações & $-0,062$ & & & & \\
\hline & Sig. & 0,849 & & & & \\
\hline & $N$ & 12 & & & & \\
\hline \multirow[t]{3}{*}{ Chefia } & Correlações & 0,389 & $-0,415$ & & & \\
\hline & Sig. & 0,211 & 0,18 & & & \\
\hline & $N$ & 12 & 12 & & & \\
\hline \multirow{3}{*}{$\begin{array}{l}\text { Natureza do } \\
\text { Trabalho }\end{array}$} & Correlações & 0,259 & $-0,007$ & 0,34 & & \\
\hline & Sig. & 0,416 & 0,983 & 0,28 & & \\
\hline & $N$ & 12 & 12 & 12 & & \\
\hline
\end{tabular}




\begin{tabular}{ll|l|l|l|l|l|l}
\hline Promoções & Correlações & 0,102 & $-0,178$ & 0,309 & 0,539 & \\
\cline { 2 - 7 } & Sig. & 0,753 & 0,581 & 0,329 & 0,07 & \\
\cline { 2 - 7 } & $\mathrm{N}$ & 12 & 12 & 12 & 12 & 12 \\
\hline \multirow{2}{*}{ Resultado } & Correlações & $-0,231$ & $-0,105$ & $-0,256$ & $-0,559$ & $-0,322$ \\
\cline { 2 - 7 } & Sig. & 0,47 & 0,745 & 0,422 & 0,059 & 0,307 \\
\cline { 2 - 7 } & $\mathrm{N}$ & 12 & 12 & 12 & 12 & 12 \\
\hline
\end{tabular}

Fonte: Dados da pesquisa

O teste de correlação de Spearman indica que nenhuma das variáveis do estudo está correlacionada, visto que nenhum coeficiente se mostrou estatisticamente significativo. Isso indica o resultado não apresenta comportamento similar ao nível de satisfação que os colaboradores atribuíram a cada dimensão analisada.

O resultado indica que, na empresa estudada, o nível de satisfação não apresenta comportamento semelhante ao resultado obtido pela agência na qual o servidor atua e vice-versa. Desse modo, conclui-se que o resultado contábil não varia na mesma proporção e nem no mesmo sentido em que o nível de satisfação dos empregados.

\section{CONCLUSÃO}

Analisando-se os dados obtidos é possível observar que a instituição possui um grande percentual de comprometimento de seus colaboradores em relação aos objetivos institucionais, alinhados com a politica de crescimento profissional que a organização possui, fortalecida pela perspectiva de crescimento profissional e organizacional.

O crescimento empresarial caminha no mesmo sentido em que a motivação dos colaboradores é fortalecida, que comprova a teoria de que uma empresa com um 
clima organizacional positivo e colaboradores motivados pode influenciar os resultados almejados, proporcionando um crescimento empresarial comprovado em suas demonstrações contábeis.

O estudo teve por objetivo verificar o nível de satisfação no trabalho e se o mesmo está correlacionado com o resultado contábil atingido. Quanto ao nível de satisfação os resultados mostram que, de forma geral, os colaboradores se mostram satisfeitos, visto que a maior parte das respostas se concentra nas notas 6 e 7 . Percebe-se que as dimensões "Relação com Colegas", "Chefia" e "Natureza do Trabalho" há maior satisfação quando comparado com as dimensões de "Salários" e "Promoções". Quanto aos "Salários", somente 9,6\% das notas ficaram concentradas na nota mais alta e nas Promoções, notou-se que 12\% dos respondentes atribuíram a menor nota para esse quesito, sendo o maior percentual concentrado nessa nota.

Para verificar a existência de relação entre Satisfação e Resultado, os dados foram inicialmente segregados por unidade de negócio e em seguida os dados foram submetidos ao teste de Correlação de Spearman. Os resultados não se mostraram significativos, evidenciando a não relação entre o Nível de Satisfação e o resultado contábil auferido.

As sociedades cooperativas têm figurado, frequentemente, entre as melhores empresas para se trabalhar, conforme pode ser visto no Portal de Cooperativismo (2020) "na edição 2018 das Melhores Empresas para Começar a Carreira, o Sicredi figura em $16^{\circ}$ lugar, entre as 45 empresas listadas, subindo seis posições em relação ao ranking do ano passado". A Revista Você S/A publica que "pelo sétimo ano consecutivo, o Sicredi está entre as 150 Melhores Empresas para Trabalhar". Na mesma linha, a Revista Amanhã, publica que o Sistema Unicred SC/PR foi premiado com esse mesmo título (www.cooperativismodecrédito.coop.br, 2020). 
As manchetes acima corroboram com o resultado dessa pesquisa ao mencionar que as empresas cooperativas têm sido positivamente avaliadas pelos seus colaboradores, demonstrando que os mesmos estão satisfeitos com suas carreiras.

Vários estudos mostram que há correlação entre satisfação dos colaboradores e produtividade ou outros indicadores de desempenho, no entanto, empresas cooperativas possuem características particulares quanto ao modelo de gestão, onde o resultado em si não é o fator primordial, inclusive pq esse tipo de sociedade é sem fins lucrativos. Nesse sentido, a satisfação do empregado pode estar correlacionada com outras variáveis como a solidificação da marca, a baixa rotatividade, baixo índice de processos trabalhistas, ou outros fatores não investigados na presente pesquisa.

Os resultados têm limitações, pois analisaram apenas um momento no tempo. Sugere-se que novos estudos sejam realizados considerando outras variáveis na pesquisa, como produtividade, cumprimento de metas, índice de rotatividade e outros indicadores de desempenho no intuito de verificar quais elementos são impactados pelo nível de satisfação no trabalho.

\section{REFERÊNCIAS}

AZEVEDO, A.J.D.; EGITO, T.D.T. Fatores que influenciam a satisfação do trabalho: um estudo de caso da Godim Imóveis. Rio Grande do Norte: UFRN, 2012.

BION, E.N. Satisfação no trabalho: um estudo de caso na biblioteca da Universidade do Vale do Itajaí no Campus de São José. 2004. 94 f. Relatório de estágio (Graduação em Automação de Escritórios e Secretariado) - Universidade do Vale do Itajaí, São José, 2004. 
GIL, A.C. Métodos e técnicas de pesquisa social. Editora Atlas. $6^{a}$ ed. São Paulo, SP. 1999.

GOULART, E. L.; RODRIGUES, C. S.; MOREIRA V. R,; WEYMER A. S. Q. A Relação Entre os Indicadores de Recursos Humanos e o Desempenho EconômicoFinanceiro das Cooperativas Agropecuárias Paranaenses, Revista de Gestão e Organizações Cooperativas - Santa Maria, RS, v.5, n.9 Jan./Jun 2018.

HEDLER, D. L., CASTRO, A. L. Satisfação do servidor público no trabalho: um estudo de caso nos centros de referência de assistência social de Paranavaí. Ciência Jurídica Empresarial. Londrina, PR. v. 16, n. 2, p.192-198, Set. 2015.

LIMA, E. M. e CORRAR, L. J. Comparação de desempenho entre as empresas melhores e maiores apontadas como melhores para trabalhar. Revista de Contabilidade do Mestrado em Ciências Contábeis da UERJ (online). Rio de Janeiro, RJ. v. 14, n. 13. P. 43. Set/Dez, 2009.

MARTINS, V.R.C. Análise da satisfação no trabalho: estudo de caso entre os funcionários da CoPP -Coordenadoria de Proteção do Patrimônio da Universidade de Brasília (Monografia do Curso de Gestão Universitária), Brasília, 2010.

MASIERO, G. Introdução a administração de empresas. São Paulo. Atlas, 2008.

MEINEN, E., PORT, M. O cooperativismo de crédito ontem, hoje e amanhã. Editora Confebras. 2012. Brasilia.

NICELETII C. D.; FABRICIO, A.; CARNEIRO, C. Satisfação no Trabalho de Colaboradores de uma Instituição Financeira Cooperativa. XXIII Seminário Internacional de Ensino Pesquisa e Extensão. Universidade de Cruz Alta - UNICRUZ, 2018. 
NODARI, C. H; BÓ, G.D; CAMARGO, M.E. Turonover e Satisfação no trabalho em uma Empresa Multinacional: Um estudo de caso. Revista Administração da UNIMEP, v.8, n.2, Maio/Agosto, 2010.

OLIVEIRA, D., CARVALHO, R. J. E ROSA, A. C. M. Clima Organizacional: Fator de Satisfação no Trabalho e Resultados Eficazes na Organização. Anais do IX Simpósio de Excelência em Gestão e Tecnologia. 2012.

PINHEIRO, M. A. H. Cooperativas de crédito: história da evolução normativa no Brasil. Editora BCB. $6^{a}$ ed. Brasília, DF. 2008.

REVISTA EXAME/VOCÊ S/A. Conheça as $\mathbf{1 5 0}$ melhores empresas para trabalhar de 2017. Disponível em: https://exame.abril.com.br/carreira/conheca-as-150-melhoresempresas-para-trabalhar-de-2017/. Acesso em 23 de março de 2018.

ROBBINS, S. P. Comportamento Organizacional. Editora Pearson Prentice hall. $11^{\text {a }}$ ed. São Paulo.

SANTOS, A dos; GOUVEIS, F.H.C; VIEIRA, P.S. Contabilidade das sociedades cooperativas: aspectos gerais e prestação de contas. Editora Atlas. $2^{a}$ ed. São Paulo 2012.

SANTOS, Eduardo da Cunha Lamounier F. et al. Satisfação no trabalho e correlação com desempenho: um estudo no instituto do meio ambiente e dos recursos hídricos do Distrito Federal. Monografia. 2012.

SESCOOP SP. Cooperativismo: Tipos de cooperativas. Disponível em: http://portaldocooperativismo.org.br/cooperativismo/4/tipos-de-cooperativa/57. Acesso em 23 de março de 2018. 
SICREDI. Conheça o Sicredi: Histórico. Disponível em: https://www.sicredi.com.br/html/conheca-o-sicredi/historico/. Acesso em 23 de março de 2018.

SIQUEIRA, M.M.M. Medidas do comportamento organizacional. Ferramentas de diagnóstico de gestão. Porto Alegre: Artmed, 2008.

O Índice de Capital Humano Watson Wyatt e o Desempenho da Empresa: Um impacto definitivo na riqueza dos acionistas. Disponível em: https://www.researchgate.net/publication/297733138_The_Watson_Wyatt_Human_Ca pital_Index_and_Company_Performance_A_definite_impact_on_shareholder_wealth. Acesso em 21 de agosto de 2018.

ORGANIZAÇÃO DAS COOPERATIVAS BRASILEIRAS. 0 que é cooperativismo. Disponível em: https://www.ocb.org.br/o-que-e-cooperativismo. Acesso em 21 de agosto de 2018 .

WAGNER, J. A; HOLLENBECK, J. R. Comportamento Organizacional: criando vantagem competitiva. São Paulo, Saraiva, 2003. 
